\title{
Human Exposure Assessment and Relief From Neuropsychiatric Symptoms: Case Study of a Hairdresser
}

\author{
Stephen J. Genuis, MD, FRCSC, DABOG, and Shelagh K. Genuis, BScOT, MLIS
}

Human exposure assessment and the results of implementing 'precautionary avoidance' suggested a relationship between a hairdresser's neuropsychiatric symptoms and occupational exposure to potentially hazardous chemicals. A variety of investigations in response to patient complaints of depression, emotional instability and various physical symptoms revealed no objective abnormality; the $\mathrm{CH}^{2} \mathrm{OPD}^{2}$ mnemonic (community, home, hobbies, occupation, personal habits, diet and drugs) recommended by the Ontario College of Family Physicians was used as a first-line screening tool to assess potential environmental exposure to toxins. After occupational leave of absence, the patient reported cessation of symptoms. Environmental causes for familiar medical problems are frequently undiagnosed; it is recommended that, where appropriate, a screening tool for evaluation of environmental exposure to toxics be incorporated into primary care assessment and management of patients. ( $\mathrm{J}$ Am Board Fam Pract 2004;17:136-41.)

The interplay between human health and the environment is garnering increased attention in the medical literature, at scientific gatherings, and in the popular press. Although it is recommended that medical students attain basic skills in eliciting an exposure history, ${ }^{1,2}$ environmental history-taking or consideration of environmental causation for common medical problems occurs infrequently in everyday clinical practice. ${ }^{3,4}$ Because "primary care practitioners often have a low index of suspicion that the source of the patient's problem may be in their environment or workplace exposure," multiple referrals are commonly made, frequently without problem resolution. ${ }^{5}$ In response to accumulating evidence of negative patient outcomes, not only from short-term exposure to toxic agents but also from long-term, low-level exposure, ${ }^{6}$ it is recommended that physicians consider environmental causation for illness, integrate environmental exposure assessment in clinical practice and "... advance precautionary practice in the presence of scientific uncertainty." 7

Submitted, revised, 9 September 2003.

From the Department of Obstetrics and Gynecology (SJG), University of Alberta, Canada (SKG). Address correspondence to Dr. Stephen Genuis, 2935-66 Street, Edmonton Alberta, Canada T6K 4C1 (E-mail: sgenuis@ incentre.net).
The objective of the following case report and discussion is to demonstrate the significant value of human exposure assessment as a first-line screening tool in the comprehensive assessment of patients presenting with neurological, emotional, or psychiatric symptoms. Although an extensive review of environmental history-taking methods is not the intent of this case report, it is interesting to note that a Medline search for medical history-taking methods relevant to environmental exposure yields little discussion of tools that are of practical value to primary care physicians. The $\mathrm{CH}^{2} \mathrm{OPD}^{2}$ mnemonic (community, home, hobbies, occupation, personal habits, diet and drugs), however, provides an efficient screening method in that it "involves searching for a change in the environment related to symptom onset or exacerbation rather than looking for a specific exposure," and it provides an organizational structure, arranged by possible source or setting, within which more direct questions are addressed. ${ }^{3}$ In the "home and hobby" category, for example, patients answer questions related to place of residence and age of home; renovations; use of pesticides or herbicides in the home, garden, or on pets; heat source within the home; use of cleaning detergents; the presence of damp or musty areas in the home, and more. ${ }^{8}$ Thoughtful completion of this screening tool is facilitated by asking patients to fill it out on their 
own time; appointment time can be used for review, discussion, and interpretation.

\section{Case Report}

A 37-year-old married woman with a history of severe premenstrual symptoms and irregular vaginal bleeding of 2 years' duration was referred to a gynecologist for evaluation. The patient reported experiencing excellent health until 2 years before, when she began to feel increasingly "emotionally unstable, irritable, and very depressed." She noted that although previously her symptoms were only evident immediately before menses, she now experienced these symptoms continuously and did not "feel like me anymore." She reported that there was no particular stress or change in her life and that, until she became depressed, she found her work to be fulfilling and enjoyed good relationships with her husband, 3 school-aged children and friends. Over the previous 2 years, the patient had been experiencing decreased libido, difficulty concentrating, diminished appetite, trouble falling asleep and early morning wakening, and decreased interest in daily life. Although she was not feeling imminently self-destructive, she stated that she saw little reason to continue living. According to the Diagnostic and Statistical Manual of Mental Disorders, 4th Edition, the patient fulfilled the criteria for a major depressive disorder. During a comprehensive physical assessment, the patient also complained of an 18-month history of debilitating fatigue, severe headaches, recurring dizziness, frequent bouts of apparently unprovoked palpitations associated with marked nausea and occasional vomiting, and intermittent visual changes, which she described as a "blinding blurriness."

The patient had previously seen 2 different family physicians and an internist who had conducted a complete neurological examination, as well as various investigations including an electrocardiogram, blood work, a chest radiograph, and computed tomography. These investigations revealed no objective abnormality. Each physician concluded that the patient had a mood disorder and recommended antidepressant therapy. It was also suggested that the patient suffered from a generalized anxiety disorder with panic attacks; pharmacological treatment was recommended. A 6-month course of a selective serotonin uptake inhibitor $(40 \mathrm{mg}$ /day paroxetine) was of minimal benefit, and a subse- quent 6-month trial of venlafaxine $(150 \mathrm{mg} /$ day $)$ failed to adequately relieve her symptoms. The patient was referred to a psychiatrist for a neuropsychiatric assessment and was awaiting her appointment. Because of the patient's insistence that a "hormonal" problem was affecting her, she was referred for gynecologic assessment.

In the process of taking a detailed history, including an occupational history, it was discovered that, after her youngest child's entrance into school 3 years before, this woman had commenced parttime work as a hairdresser. She emphasized that before the onset of depressive symptoms, the interaction with clients had been very enjoyable and that she had experienced great satisfaction in her work. At the time of assessment, she was working an average of 5 days per week for approximately 4 hours each day in a small, poorly ventilated room in her home. With no other cause evident for her gynecologic complaints and apparently deteriorating health, the $\mathrm{CH}^{2} \mathrm{OPD}^{2}$ mnemonic ${ }^{3}$ was used as a first-line screening tool in the assessment of potential environmental exposure to toxins. Results of the environmental exposure history indicated that over the preceding 5 years, there had been no significant changes in the patient's environment, except in the area of occupation: the patient reported that for the past 3 years she had experienced routine exposure via inhalation and direct skin contact to hairdressing products such as hair sprays, dyes, bleaches, permanent wave solutions, shampoos, and conditioners. Although the patient had not considered her exposure to these chemicals to be medically significant, concerns about the impact of the chemical ingredients of standard hairdressing products on hairdressers has been well documented in the medical literature. ${ }^{9-19}$

Physical examination revealed no obvious abnormality, and hormonal markers were within normal range; the environmental exposure history indicated that symptoms had commenced and worsened while the patient was working as a hairdresser. These results were discussed with the patient and temporary, precautionary avoidance of the occupational environment was suggested as a means of exploring the possibility that chemical exposure was associated with the neuropsychiatric and other symptoms experienced by the patient. Follow-up with expert assessment of the workplace environment and potential workplace modification was also suggested. Because the patient had no 
personal or family history of psychiatric illness and was personally convinced that there was a relatively recent cause for her various health complaints, she chose to commence a 1-month leave of absence from her hairdressing business to determine whether neuropsychiatric symptoms would be alleviated.

After 2 weeks of avoiding the job-related environment, the patient complained of boredom, but reported that her mood had improved substantially, thoughts related to the futility of life were no longer present, and physical symptoms, such as visual disturbances, nausea, dizziness, and heart palpitations, were occurring infrequently. At the end of the 1-month occupational reprieve, the patient stated that she felt " $80 \%$ better," that her sleep disturbance had resolved, and that she was experiencing a return to normal energy levels. The patient concluded that her hairdressing career was hazardous to her health and that the latter was "more important than any job."

Although expert assessment of the workplace (with possible use of Material Safely Data Sheets to determine specific substances causing symptoms) as well as alternative work environments (such as a move from a home-based business to a commercial setting with potentially better adherence to workplace safety regulations) were discussed, the patient stated that she did not wish to risk compromising her improved health and well-being. She seemed to have already made a decision to pursue an alternate occupation. Three months later, the patient canceled her follow-up appointment because, as she reported in a telephone conversation with the first author, she felt wonderful, she was no longer experiencing neuropsychiatric and other problematic symptoms, and she was busy with new employment. Although she stated that she missed her previous clientele and her work as a hairdresser, the patient sounded upbeat and very positive about her future prospects. Twelve and 24 months later, the patient reported that she was feeling well and had had no reoccurrence of any of the previous health complaints.

\section{Literature Review and Discussion}

In this literature review and discussion, the following issues will be explored: the occupational chemical exposure of hairdressers and the importance of occupational history-taking; support for the associ- ation between physical and neuropsychiatric symptoms and occupational exposure in the presented case; the value of a first-line, environmental exposure assessment tool for primary care and specialist physicians as well as the need for expert follow-up assessment; and the role of precautionary avoidance as a means of diagnosing association between exposure and symptoms.

\section{Occupational Chemical Exposure of Hairdressers}

A review of the medical literature on the potential occupational exposure of hairdressers reveals that there is a range of chemical hazards in this working environment "many [of] which are either known or suspected allergens, mutagens, and/or carcinogens." 19 This job-related exposure has been associated with a number of health concerns, primarily skin disorders, ${ }^{9-12}$ respiratory conditions, ${ }^{12-16}$ and cancer. ${ }^{17-19}$ Although correlation between hairdressing chemicals and neuropsychiatric symptoms has not been documented in the medical literature thus far, it is recognized that neurotoxicants can express themselves in a "plethora of possible endpoints," including neurobehavioral manifestations. ${ }^{20}$ Depression occurring as a direct result of chemical exposure has been noted in the literature. ${ }^{5}$ Given that "environmental health problems frequently present as common medical problems," it is crucial that physicians determine whether patients, especially those experiencing otherwise unexplained health problems, are being exposed to potentially hazardous substances and, if chemical exposure is discovered, that action is taken to further evaluate and therapeutically address the problem.

The medical literature indicates that hairdressers are at definitive risk for occupational chemical exposure and that this risk is exacerbated because many work in unventilated spaces ${ }^{21}$ and the industry is largely unregulated, nonunionized, and composed of small businesses. ${ }^{19}$ Despite training received through educational programs at community colleges and private training institutions, most hairdressers are not cognizant of their workrelated exposure to potentially hazardous chemicals $^{19}$ and have, therefore, not focused on proactively minimizing contact with these substances. Legislative and intensified preventive measures have been documented as having a positive impact on hairdressers' occupational skin disease ${ }^{10}$; it has also been reported that many persons working in 
this industry simply choose alternate careers when experiencing a wide variety of health complaints, which they assess as being linked to their work environment. ${ }^{9}$ Because women's occupational histories are frequently overlooked in medical historytaking, ${ }^{22}$ it is particularly important that clinicians use a screening tool such as the $\mathrm{CH}^{2} \mathrm{OPD}^{2}$ mnemonic to ensure that all aspects of a patient's potential exposure to environmental contaminants are evaluated.

\section{Neuropsychiatric Symptoms and Occupational Exposure}

It may be suggested that, in this case study, the patient's symptoms were psychosomatic and that when she took a temporary leave of absence from her job, she spontaneously improved because of emotional or subconscious psychological factors. As is the situation for many cases involving neuropsychiatric symptoms, this theory cannot be conclusively disproved. A psychosomatic explanation, however, is not likely for the following reasons: (1) the patient enjoyed being a hairdresser, she chose precautionary avoidance of her work environment as a temporary means of assessment, and, if it were not for her appreciably improved health, she stated that she would have chosen to return to this work; (2) despite a history of deteriorating health, both her nonpsychiatric (including visual, neurological, cardiovascular, and gastrointestinal complaints) as well as psychiatric symptoms resolved when exposure to the potentially hazardous chemicals was eliminated; (3) the chemical agents involved in her occupation are recognized in the medical literature as having a range of adverse health effects; (4) no precipitating emotional stressors were noted in the patient's history; (5) in the 2 years that have passed since precautionary avoidance was initiated, the patient has not experienced a recurrence of symptoms despite her less preferred, subsequent employment; and (6) the patient had no past personal or family history of psychiatric illness or emotional instability.

\section{Environmental Exposure Assessment by Primary Care Physicians}

The $\mathrm{CH}^{2} \mathrm{OPD}^{2}$ mnemonic, available from the Ontario College of Family Physicians website ${ }^{8}$ is a valuable first-line exposure assessment tool for primary care and specialist physicians in that it provides an uncomplicated and effective means of as- sessing exposure to hazardous substances and may indicate underlying cause for patients with either familiar medical problems or with multiple symptoms in the absence of discernible pathology. Although expert evaluation may be an important subsequent step to environmental or occupational assessment by a family doctor, the following benefits of a simple exposure history by the primary care physician have been noted: it "may be the key to identifying the patient's current illness," it is a tool that develops the patient-physician relationship as discussion of basic personal facts facilitates potentially intimidating interactions with physicians, and it allows for "future-focused evaluation of organ systems that may be at particular risk because of prior exposures." Because of the increasing spectrum of health sequelae that may be attributed to toxic exposure, ${ }^{3,7,23-29}$ and because the rapidly expanding field of human exposure assessment is still relatively new to many physicians, ${ }^{30,31}$ the utilization of a user-friendly, first-line tool is a valuable means by which physicians can identify potential hazardous exposure.

Expert evaluation of the work environment and identification of specific chemicals involved in the process as well as evaluation of exposure pathway should follow this environmental assessment, because expert appraisal may allow the identification of specific variables within the work environment that can be modified to reduce or eliminate exposure to toxins. Although the patient in this case study declined expert assessment and chose to adopt precautionary avoidance not only as a means of confirming the association between symptoms and occupational environment but also as a longterm therapeutic measure, it must be noted that precautionary avoidance on a long-term basis may involve significant personal costs; therefore, expert involvement may be recommended to facilitate diagnosis and therapy for specific environmental exposures. Expert assessment also serves public health objectives of preventing potential hazard to others and facilitating the comprehensive evaluation of products being used in a given industry.

\section{Precautionary Avoidance}

It is important to note that precautionary avoidance is a recognized method of diagnosing association between exposure and symptoms., ${ }^{3,24}$ Although a causal relationship between the patient's exposure and her symptoms cannot be conclusively demon- 
strated, the documented association between a variety of physical illnesses and the hairdressing occupation as well as the patient's dramatic response to precautionary avoidance makes it reasonable to hypothesize that this patient's physical and neuropsychiatric symptoms were associated with environmental exposure related to her occupation. Although rechallenging the patient to the primary occupational environment might be one way to strengthen the association between exposure and symptoms, there may be "an adverse psychological response... where there has been recovery from the direct toxic effects"; it has been documented that some victims of toxic re-exposure suffer from post-traumatic stress disorder. ${ }^{32}$ Other investigations that would strengthen the diagnosis of neurotoxic exposure include neuropsychological testing; ${ }^{33}$ neuropsychiatric assessment such as the Minnesota Multiphasic Personality Inventory (which has been used in psychosomatic research and "may also be a useful instrument in detecting changes in psychological and personality functioning following neurotoxic exposure"); ${ }^{32}$ and, given the documented sensitivity of visual cones to neurotoxic exposures, formal documentation of the patient's visual changes via visual cone assessment. ${ }^{34,35}$

Although physicians and other health care providers "have been largely uninvolved in environmental issues related to human health,"2 even physicians with little formal training or experience in this area can use environmental exposure assessment and precautionary avoidance as a means of determining potential environmental disease. Although it is not uncommon that patients are unaware of potential environmental hazards, particularly when caused by long-term or low-dose exposure, it is critical that physicians consider environmental cause when presented with diffuse, time-specific, or unexplainable symptoms.

\section{Conclusion}

Physicians have reported a low level of knowledge about environmental health issues ${ }^{31}$; consequently, environmental causes for familiar medical problems are frequently overlooked. In light of the thousands of industrial chemicals present in our environment, ${ }^{23,36}$ it is important that clinicians move beyond diagnosis of symptoms and, by incorporating environmental exposure assessment into appropriate medical examinations, gather information that may allow the identification of underlying illness causation and effective symptom relief.

\section{References}

1. Merritt EF. Human health and the environment: are physician educators lagging behind? JAMA 1999; 281:1661.

2. Pope AM, Rall DP, editors. Environmental medicine: integrating a missing element into medical education. Washington DC: National Academy Press; 1995.

3. Marshall L, Weir E, Abelsohn A, Sanborn MD. Identifying and managing adverse environmental health effects: 1 . Taking an exposure history. CMAJ 2002;166:1049-55.

4. Kilpatrick N, Frumkin H, Trowbridge J, et al. The environmental history in pediatric practice: a study of pediatricians' attitudes, beliefs, and practices. Environ Health Perspect 2002;110:823-7.

5. Frank AL. Approach to the patient with an occupational or environmental illness. Prim Care 2000;27: 877-94.

6. Coury D. Biological influences on brain and behavior. Pediatric Academic Societies' Annual Meeting: Adolescent Medicine; 2001 May 1; Baltimore, Maryland.

7. Weir E. Identifying and managing adverse environmental health effects: a new series. CMAJ 2002;166: 1041-3.

8. Marshall LM. Exposure history. Ontario College of Family Physicians. Available at: URL: http://www.ocfp. on.ca/local/files/EHC/Exposure\%20Hx\%20Forms. pdf.

9. Holm JO. An epidemiological study of hand eczema. VI. A follow-up of hairdresser trainees, with the focus on various health complaints. Acta Derm Venereol Suppl (Stockh) 1994;187:26-7.

10. Dickel H, Kuss O, Blesius CR, Schmidt A, Diepgen TL. Occupational skin diseases in Northern Bavaria between 1990 and 1999: a population-based study. Br J Dermatol 2001;145:453-62.

11. Marks JG Jr. Occupational skin disease in hairdressers. Occup Med 1986;1:273-84.

12. Yawalkar N, Helbling A, Pichler CE, Zala L, Pichler WJ. T cell involvement in persulfate triggered occupational contact dermatitis and asthma. Ann Allergy Asthma Immunol 1999;82:401-4.

13. Albin M, Rylander L, Mikoczy Z, et al. Incidence of asthma in female Swedish hairdressers. Occup Environ Med 2002;59:119-23.

14. Leino T, Tammilehto L, Luukkonen R, Nordman H. Self reported respiratory symptoms and diseases among hairdressers. Occup Environ Med 1997;54: 452-5.

15. Nagata N, Kawajiri T, Hayashi T, Nakanishi K, Nikaido Y, Kido M. Interstitial pneumonitis and 
fibrosis associated with the inhalation of hair spray. Respiration 1997;64:310-2.

16. Blainey AD, Ollier S, Cundell D, Smith RE, Davies RJ. Occupational asthma in a hairdressing salon. Thorax 1986;41:42-50.

17. Boffetta P, Anderson A, Lynge E, Barlow, Pukkala E. Employment as hairdresser and risk of ovarian cancer and non-Hodgkin's lymphoma. J Occup Med 1994;36:61-5.

18. Pukkala E, Nokso-Koivisto P, Roponen P. Changing cancer risk pattern among Finnish hairdressers. Int Arch Occup Environ Health 1992;64:39-42.

19. Winder C. Chemical hazards and health effects of hairdressing. J Occup Health Safety 1993;9:359-71.

20. Weiss B. A risk assessment perspective on the neurobehavioral toxicity of endocrine disruptors. Toxicol Indus Health 1998;14:341-59.

21. Hollund BE, Moen BE. Chemical exposure in hairdresser salons: effect of local exhaust ventilation. Ann Occup Hyg 1998;42:277-82.

22. McCurdy SA, Morrin LA, Memmott MM. Occupational history collection by third-year medical students during internal medicine and surgery inpatient clerkships. J Occup Environ Med 1998;40:680-4.

23. Solomon GM, Schettler T. Environment and health: 6. Endocrine disruption and potential human health implications. CMAJ 2000;163:1471-6.

24. Marshall L, Weir E, Abelsohn A, Sanborn MD. Occupational and environmental exposure. CMAJ 2002;167:744-6.

25. Olsen SF. Mercury. PCB, and now eicosapentaenoic acid: still another reason why pregnant women should be concerned about eating seafood? Int J Epidemiol 2001;30:1279-80.

26. Gasiewicz TA. Exposure to dioxin and dioxin-like compounds. Ment Retard Dev Disabil Res Rev 1997; 3:230-8.

27. Charlier C, Albert A, Herman P, et al. Breast cancer and serum organochlorine residues. Occup Environ Med 2003;60:348-51.

28. Gorell JM, Johnson CC, Rybicki BA, Peterson EL, Richardson RJ. The risk of Parkinson's disease with exposure to pesticides, farming, well water, and rural living. Neurology 1998;50:1346-50.

29. Osteen KG, Sierra-Rivera E. Does disruption of immune and endocrine systems by environmental toxins contribute to development of endometriosis? Semin Reprod Endocrinol 1997;15:301-8.

30. Ott WR. Human exposure assessment: the birth of a new science. J Expo Anal Environ Epidemiol 1995; $5: 449-72$.

31. Sanborn MD, Scott EAF. Environmental health concerns in urban and rural family practice. Can Fam Physician 1998;44:1466-72.

32. Bolla KI, Roca R. Neuropsychiatric sequelae of occupational exposure to neurotoxins. In: Bleecker ML, editor. Occupational neurology and clinical neurotoxicology. Baltimore: Williams \& Wilkins; 1994. p. 133-59.

33. Agnew K, Masten VL. Neuropsychological assessment of occupational neurotoxic exposure. In: Bleecker ML, editor. Occupational neurology and clinical neurotoxicology. Baltimore: Williams \& Wilkins; 1994. p. 113-31.

34. Mergler D. Neurotoxicology of the visual system: early indications of visual dysfunction. In: Bleecker ML, editor. Occupational neurology and clinical neurotoxicology. Baltimore: Williams \& Wilkins; 1994. p. 161-72.

35. Striph GG, Miller NR. Neurotoxicology of the visual system: Clinical evidence and concerns. In: Bleecker ML, editor. Occupational neurology and clinical neurotoxicology. Baltimore: Williams \& Wilkins; 1994. p. 172-86.

36. Wigle D. Child health and the environment. Patient Care Canada 2000;11:54-62. 